\title{
A Practical Exploration of Blended Teaching in SPOC-Based “Circuit Analysis" Course
}

\author{
Lijuan Zhu, Qiaoying Tong \\ School of Physics and Electronic Engineering, Yancheng Teachers University, Yancheng, China \\ Email: junxue0618@163.com
}

How to cite this paper: Zhu, L. J., \& Tong, Q. Y. (2022). A Practical Exploration of Blended Teaching in SPOC-Based "Circuit Analysis" Course. Open Journal of Social Sciences, 10, 199-210.

https://doi.org/10.4236/jss.2022.101018

Received: December 20, 2021

Accepted: January 17, 2022

Published: January 20, 2022

Copyright $\odot 2022$ by author(s) and Scientific Research Publishing Inc. This work is licensed under the Creative Commons Attribution International License (CC BY 4.0).

http://creativecommons.org/licenses/by/4.0/

\begin{abstract}
In view of the problems of the traditional teaching mode, the SPOC (small private online course)-based hybrid teaching mode and the teaching practice exploration in the circuit analysis course were carried out among the 19-level undergraduate students of electrical engineering and its automation in conjunction with the school's SPOC platform project of Circuit Analysis. The practice shows that the SPOC-based hybrid teaching mode has realized the transformation from teacher teaching-centered to student learning-centered, from classroom-based to combined classroom and extracurricular, from result-based to combined process evaluation and result, and more effectively cultivated students' independent learning ability and improved teaching quality and teaching efficiency.
\end{abstract}

\section{Keywords}

SPOC, Blended Learning, Self-Directed Learning

\section{Introduction}

Circuit analysis is a very important professional foundation course for electronics and electrical majors in our university, and it is also a very theoretical and practical course. Its theory and methods play a necessary role in supporting the knowledge system of subsequent courses. At the same time, circuit analysis has many basic knowledge points, strong theory, and teaching practice is difficult to break through the traditional form. In order to ensure the teaching effect, the teaching mode of circuit analysis course urgently needs to be reformed (Zhang, 2020). As a small-scale online course, SPOC integrates project design, knowledge explanation and other links into the SPOC network platform, which can improve students' enthusiasm, cultivate students' autonomous learning ability, and improve teaching quality and efficiency. 
At present, with the further deepening of teaching reform, the talent training program is also constantly adjusted, and the theoretical class hours of circuit analysis course in our school are continuously compressed. On the other hand, the teaching content of the circuit analysis course is more, which is an important guarantee for the follow-up study of basic technical courses and professional courses. The contradiction that the content of the circuit analysis course has many hours is especially prominent (Wang, 2018). The traditional teaching class mainly relies on the teacher's explanation, which is basically in the form of "full house irrigation". Although multimedia teaching has been widely used at present, the multimedia technology of picture, text, sound and animation makes the classroom lively and easy for students to understand and accept knowledge, which solves the disadvantages of the traditional teaching mode, but it still takes teacher teaching as the theme, students still accept learning passively, and students' interest in learning is not high (Li, Fu, Yin, \& Chen, 2018). Before this, the teaching of circuit analysis in our university has always followed the traditional teaching mode. Students generally reflected that the contents of the class were boring and difficult to understand, and it was also very difficult to do questions after class, not to mention the combination of theory and practice. These have a direct impact on the teaching objectives of the course. Based on this, the circuit course group of the School of Physics and Electronic Engineering of our university applied for the circuit analysis course construction project based on SPOC cloud platform, and carried out teaching practice exploration among the 19th undergraduate students of Electrical Engineering and its Automation, which provided a new idea and method for the teaching of circuit analysis course.

This new teaching method takes students as the main body and realizes the transformation from the teacher "teaching" as the center to the students "learning" as the center ( $\mathrm{Yu}, 2015)$. The "student-centered" can give full play to each student's initiative and enthusiasm in learning, and make students always in an efficient learning state. After a semester of operation, remarkable teaching effects have been achieved.

\section{SPOC-Based Hybrid Teaching Platform}

SPOC (small private online course), that is, small-scale restricted online course (Fox, 2013). It has the advantages of abundant learning resources and flexible learning time and space, and at the same time, it has the characteristics of small capacity of online course, the target students of the university or related majors, high learning motivation of students, teachers can supervise students by organizing flipped classroom, etc., and it is easy to realize the teaching according to the material (Wang \& Yi, 2021).

SPOC-based hybrid teaching mode is increasingly popular among college teachers (Xie, Sun, \& Yu, 2017, Zhang, Zhang, Tang, \& Yu, 2016) some universities have established many SPOC courses, and we have built dozens of SPOC courses in Yancheng Normal College, and the circuit analysis course is our ap- 
proved SPOC course construction project in 2017. The beginning of the course construction has been exploring how to closely link online and offline teaching, after 2018 began to try SPOC-based flipped classroom teaching hybrid teaching reform and case study method in circuit analysis, 2019 has completed the production of all materials for the SPOC course, the spring semester of 2020 to fully carry out the SPOC-based hybrid teaching in the circuit analysis course Practical application, the blended teaching model is shown in Figure 1.

\section{Construction of SPOC Platform for Circuit Analysis}

The circuit analysis SPOC course uses the school cloud provided by the Love Course website as the teaching platform, that is, the SPOC platform. In the early stage, our circuit analysis teaching team spent nearly three years completing the circuit analysis SPOC course construction, which mainly includes the teaching content design of the course, the presentation of the course content, the evaluation criteria of the course, and the learning interaction and communication.

Firstly, the teaching content is designed according to the teaching objectives and talent training objectives of the course. The teaching content of the course is optimized, that is, modularized, and divided into four modules: resistive circuit module, dynamic circuit module, sinusoidal steady-state circuit module, and three-phase circuit module. Under each module corresponds to several chapters, and each chapter is selected to explain the knowledge points. The teaching content is from shallow to deep, from DC to AC, from single-phase AC circuit analysis to three-phase AC circuit, from stable circuit model analysis to dynamic circuit response analysis, and the loop is interlocked to fit the realization of teaching objectives.

Second, the course content is built in the SPOC platform. It is mainly based on micro-lessons (micro-videos), documents, rich text materials, unit quizzes and assignments and assignment evaluation and grading criteria. A total of 41 micro-videos with duration of 629 minutes, 70 documents of supporting resources such as courseware and micro-lesson learning task sheets, 10 unit quizzes and 10 unit exercises were produced.

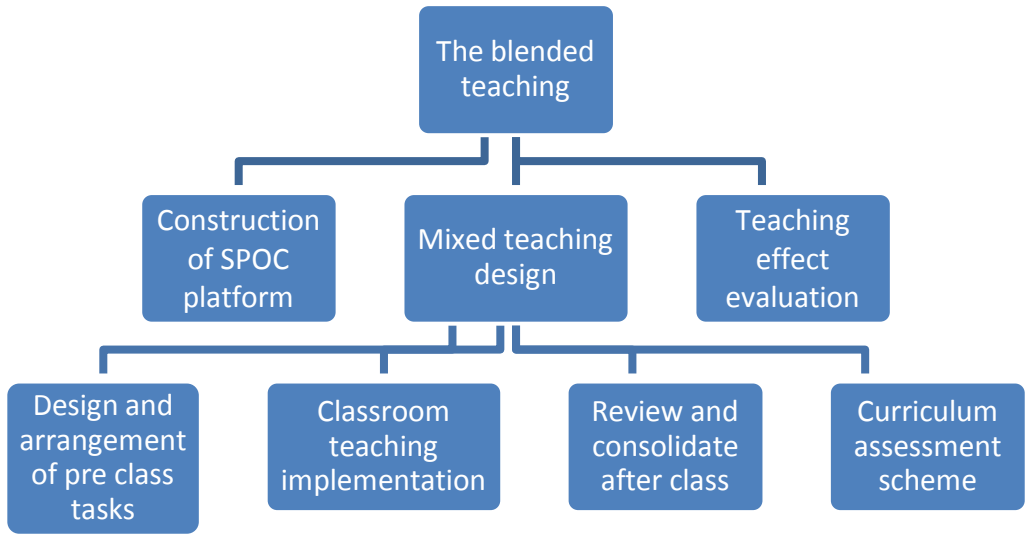

Figure 1. The blended teaching model. 
Again, the evaluation criteria of the course are designed. The evaluation criteria mainly include the evaluation of the effect of independent learning before class, the evaluation of classroom learning and classroom activity, the completion of post-class assignments, the evaluation of special seminars, and the final examination, which are converted into the total course assessment grade of the course according to the proportion of these five aspects.

Finally, communicate with students about learning. Question discussion is a feature of the SPOC course, where teachers and students grow together and progress together through research and discussion. The SPOC platform discussion, SPOC platform accompanying quiz, MU classroom accompanying discussion and $\mathrm{MU}$ classroom accompanying quiz are available for interactive communication. In addition, the SPOC platform also has an evaluation of the effectiveness of students' learning on the platform, which facilitates timely adjustment and improvement of the teaching design program. The SPOC platform is shown in Figure 2.

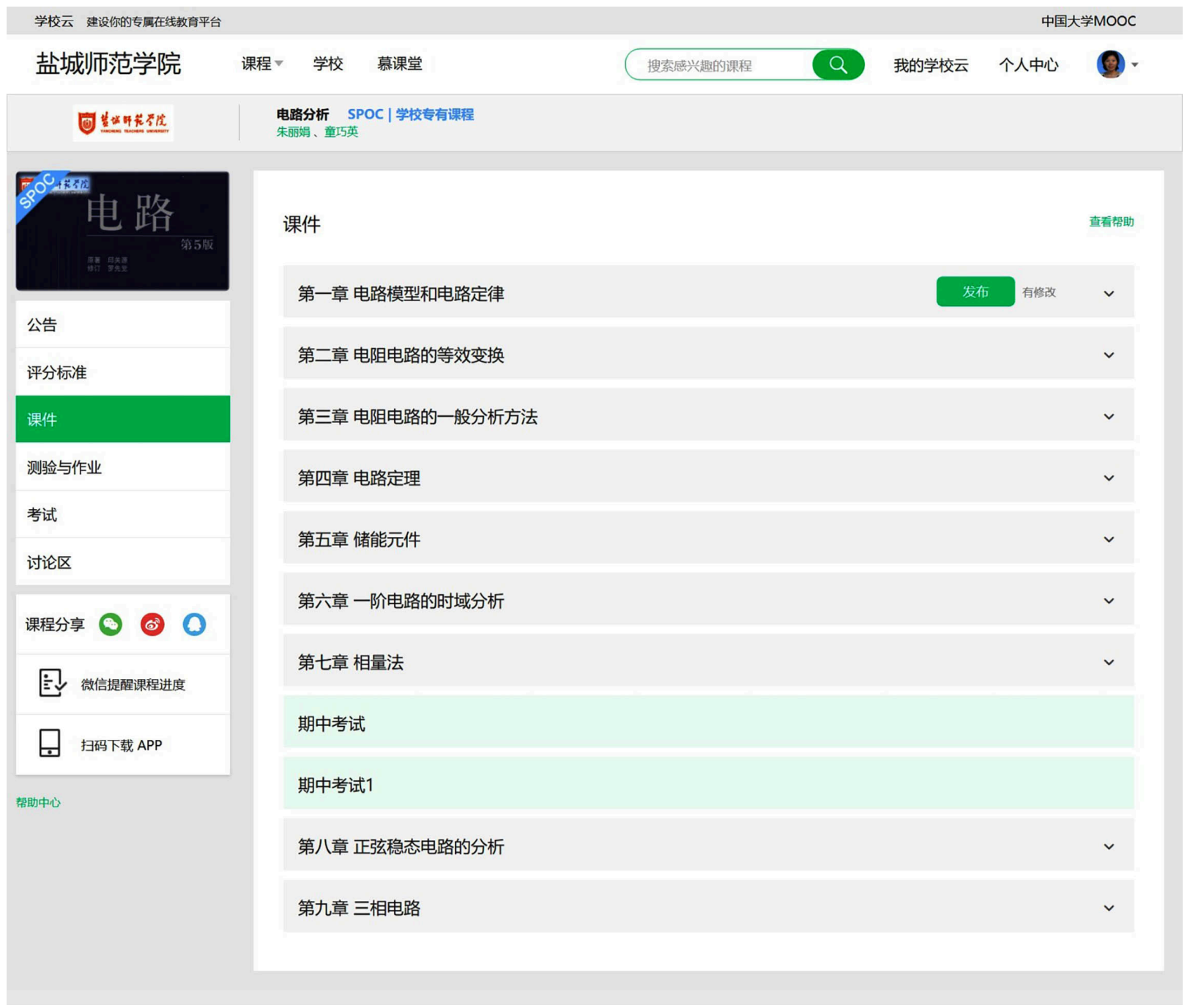

Figure 2. The SPOC platform. 


\section{Mixed Teaching Design of Circuit Analysis Course Based on SPOC}

The curriculum mixed teaching design based on SPOC mainly includes five links (Sun \& Ding, 2019): the design and arrangement of pre-class tasks, classroom teaching facilities, consolidation exercises after class, curriculum assessment scheme and channels for real-time communication with students. The task, organization form, time allocation of each link and the time's connection between each link needs to be carefully designed by teachers.

\subsection{Design and Arrangement of Pre-Class Tasks}

Pre-class task design is the basis for the successful implementation of mixed teaching of SPOC course. According to the teaching schedule, the micro class learning task list that students need to complete for each teaching content is designed, and it is released to students through SPOC platform announcement or QQ learning group at least one week before the teaching. The micro class learning task list includes learning objectives, learning contents, autonomous learning methods and the address of learning reference resources. At the same time, there is space in the task list for students to record the confusion encountered during learning or practice. The arrangement of curriculum tasks includes students' autonomous learning and autonomous evaluation summary.

1) Students' autonomous learning

According to the requirements in the learning task list, students can log in to the SPOC cloud platform of the school and watch the micro-video. If a part of the micro class cannot be understood, they can consult the relevant resources provided by the teacher to supplement their learning or fill in the confusion they encounter in the task list to be submitted to the teacher; After the micro-video of each knowledge point, there are four to five test questions, which can help students test their mastery of knowledge points and judge whether their understanding is correct. In the learning process of SPOC platform, students can discuss with each other in the discussion area about problems they don't understand or are interested in, and teachers can also participate in the discussion and answer questions in the Q\&A area of SPOC platform; Through autonomous learning and testing, the absorption and digestion of learning content are preliminarily completed.

2) Summary of autonomous learning evaluation

The SPOC platform will conduct statistical processing on the students' answers to the test questions. Teachers can see the correct rate of each test question and the answers of each student, so as to grasp the difficulties of students' learning in time. According to the completion of the test questions, the problem discussion in the discussion area and the puzzles raised by the students in the learning task list, the teacher makes a preliminary evaluation of the students' learning situation, and analyzes and summarizes which problems need to be emphasized or expanded again in the classroom. 


\subsection{Classroom Teaching Implementation}

Classroom-focused learning is a two-way interactive process composed of teachers' teaching and students' learning. The most beneficial change to students' learning is still in classroom activities. According to the learning status of students in SPOC platform before class, teachers must carefully design the contents in class, including communication, explanation, guidance, exploration, supervision, Q\&A and other processes. Before classroom teaching, teachers use the classroom function in SPOC platform to create a classroom and add teaching activities such as check-in, in-class practice and discussion in the classroom. Students study in class according to the timetable.

\subsubsection{Check the Learning Effect and Consolidate the Basic Knowledge}

In classroom intensive learning, first briefly lead the students to sort out the basic knowledge points in the micro class, and then strengthen the students' understanding of these basic knowledge points in the form of questions. You can also use $\mathrm{Mu}$ classroom to practice in class to test the effect of autonomous learning before class.

\subsubsection{Answer Questions, Solve Doubts and Internalize Knowledge}

Teachers summarize the puzzles and solutions of micro exercises fed back by students in the learning task list, put forward common problems, organize students to discuss based on examples, and strengthen the mastery of basic knowledge; For the questions raised by individual students, first, answer them, then drive them, guide them to think deeply and comprehensively, and broaden the breadth and depth of knowledge. The questions raised in the process of answering questions and solving doubts must be cleverly designed, the difficulty can be improved or the application can be expanded, and new knowledge points can be extended. The premise is that they should be closely related to practical application, so as to promote students' Internalization of knowledge, so as to improve their ability to solve problems in practical application.

Summary and comments: According to the real-time documents recorded on the platform, teachers summarize the students' mutual evaluation or objectively describe the completion quality, as well as the common problems existing in the implementation, and conduct the second evaluation.

\subsubsection{Mixed Teaching Method of Circuit Analysis Based on SPOC}

The mixed teaching method based on SPOC includes the mixing of a variety of teaching environments, a variety of teaching ideas, a variety of teaching methods, a variety of teaching resources, a variety of teaching styles, a variety of teaching evaluation methods, and so on. The main methods involved in hybrid teaching are: flipped classroom teaching method, case teaching method, problem-based teaching method, task-driven method and so on.

1) Flipped classroom teaching method

Before class, students use the teaching resources released by SPOC platform to study independently, and conduct interactive communication between teachers 
and students and students in class, including answering questions and solving doubts, the application of knowledge, etc. For the content that is difficult to understand and practical, flip teaching is carried out in the classroom.

For example, flipped classroom teaching is used in superposition principle knowledge points. First, before class, students learn the concept, proof process and general steps of superposition theorem through micro-video, master the concept of superposition theorem and understand the process of theorem proof. Then, when explaining in class, you only need to briefly explain the concept and application steps of the theorem. Carry out on-site practice and explanation, analyze examples while learning knowledge points, and learn and think while learning. Finally, through several practical exercises, we can understand the application of superposition theorem from multiple angles. It can be seen that in the flipped classroom based on SPOC, we no longer prove the concepts of basic theorems, but spend most of our time in different applications of theorems to practice with examples. In the process of example practice, students can ask questions at any time and teachers can answer them in class. This method not only achieves good teaching effect, but also solves the problem of more content and fewer class hours of circuit analysis course.

2) Case teaching method

Circuit analysis is highly theoretical and closely combined with practice. For learning more difficult knowledge points, the course teaching team collectively prepares lessons and designs typical circuit teaching cases in life.

For example, when explaining that the general connection method of three-phase circuit is three-phase four wire system, explain the ubiquitous three hole socket. In the three holes, the single hole at one end is connected to the ground wire, and the two holes at the other end are connected to the end wire and the centerline. After the theoretical introduction, the following cases are led out.

Case: an old man has an electric rice cooker at home, which has been used for seven or eight years. Recently, there are problems with the electric rice cooker. Sometimes when cooking, he will encounter the shell and get an electric shock. So the old man took the rice cooker to repair. If you are maintenance personnel, how should you check and repair it? What may be the problem?

Through the analysis, teaching and training of this case, we can understand the theoretical knowledge more thoroughly, and fully combine the theory with practical application, so as to improve the cultivation of students' practical ability.

3) Problem-based teaching method

Create situations and ask questions in micro classes or classes. Students integrate their original knowledge, solve problems under the guidance of teachers, find new problems, and then find solutions.

For example, in explaining the knowledge points of phasor method, how to calculate the sum of two sinusoidal AC currents with the same frequency? And what are the characteristics of the results of observation and summary summa- 
tion? The phasor representation of sinusoidal quantity is obtained step by step, so as to cultivate students' problem-solving skills and improve their ability of autonomous learning and thinking.

4) Task-driven approach

The new knowledge to be learned is cleverly hidden in the task, and the mainline of teaching is to complete the task. After recognizing and analyzing the task, students formulate solutions, use necessary learning materials, and actively explore and implement the task independently, so as to improve their ability of autonomous learning and problem analysis.

\subsection{Review and Consolidate after Class}

Students have basically mastered the relevant theoretical knowledge in "circuit analysis" through pre-class and in-class learning. They can log in to SPOC platform at any time for repeated online learning to consolidate and strengthen the knowledge points they do not understand. However, in order to really learn this course well, it is also necessary to carry out some intensive training after class in the form of homework. Unit tests, unit assignments and examinations are important links in the implementation of curriculum reform based on SPOC courses, and are important means to test students' mastery of knowledge points and skills. At the end of each week's knowledge points, unit tests and unit assignments corresponding to the knowledge points learned this week are arranged, and final practice exams are also set. These must be completed within the specified time limit. Among them, unit tests are objective questions such as selection, blank filling and judgment, and the test results are directly given in SPOC platform. Unit exercises are subjective questions. In the platform, students can be set to conduct self-evaluation and mutual evaluation, and teachers can also be set to correct.

\subsection{Curriculum Assessment Scheme}

In order to effectively guide students to study independently, the circuit analysis course assessment runs through the whole learning process. The assessment adopts the combination of learning process assessment and final assessment to establish a set of learning assessment and evaluation standards, that is, the total score of circuit analysis = learning process assessment and evaluation ${ }^{\star} 60 \%+\mathrm{fi}$ nal assessment ${ }^{\star} 40 \%$, of which, the learning process evaluation consists of four parts: $30 \%$ of the time spent in attendance and watching videos, $10 \%$ of the time spent in discussion on SPOC platform, $20 \%$ of the online unit tests and $40 \%$ of the online unit exercises. After the course, the process assessment and evaluation score data can be directly exported from the SPOC platform. The main purpose of formulating this diversified curriculum assessment system is to urge students to actively participate in autonomous learning, to avoid being unable to complete learning tasks in time because of laziness, and to stimulate students' initiative and enthusiasm in learning. The results of students' classroom attendance, 
classroom activities, classroom lists, classroom performance and independent SPOC learning performance can be seen online, as shown in Figure 3 and Figure 4.

\section{课堂榜单}

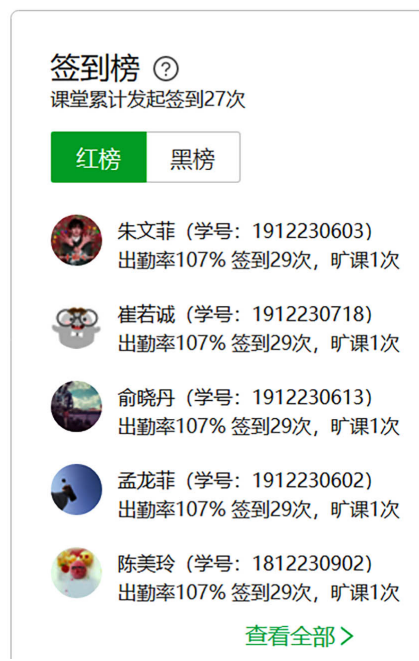

答题榜 (?)

课堂累计发布了0题

\section{红榜 黑榜}

ary 陈俊豪 (学号: 1912230719) 正确率 $0 \%$ 答对 5 题

刘翰林 (学号: 1912230629) 正确率 $0 \%$ 答对 5 题

2 陆启杭 (学号: 1912230628) 正确率 $0 \%$ 答对 5 题

- 田歆雨 (学号: 1912230702) 正确率 $0 \%$ 答对 5 题 谢诗芸 (学号: 1912230609) 正确率 $0 \%$ 答对 5 题

查看全部>

Figure 3. Class list.

\begin{tabular}{|c|c|c|}
\hline प & 备课区 & \\
\hline 国 & 教学日志 & \\
\hline ৫ে & 学情统计 & \\
\hline$: \equiv$ & 学生成绩 & \\
\hline$\theta$ & 资源库 & $\checkmark$ \\
\hline (2) & 帮助中心 & \\
\hline
\end{tabular}

$$
\begin{aligned}
& \text { 学习表现 成绩汇总 } \\
& \text { 学生视频学习相关数据隔天更新。 }
\end{aligned}
$$

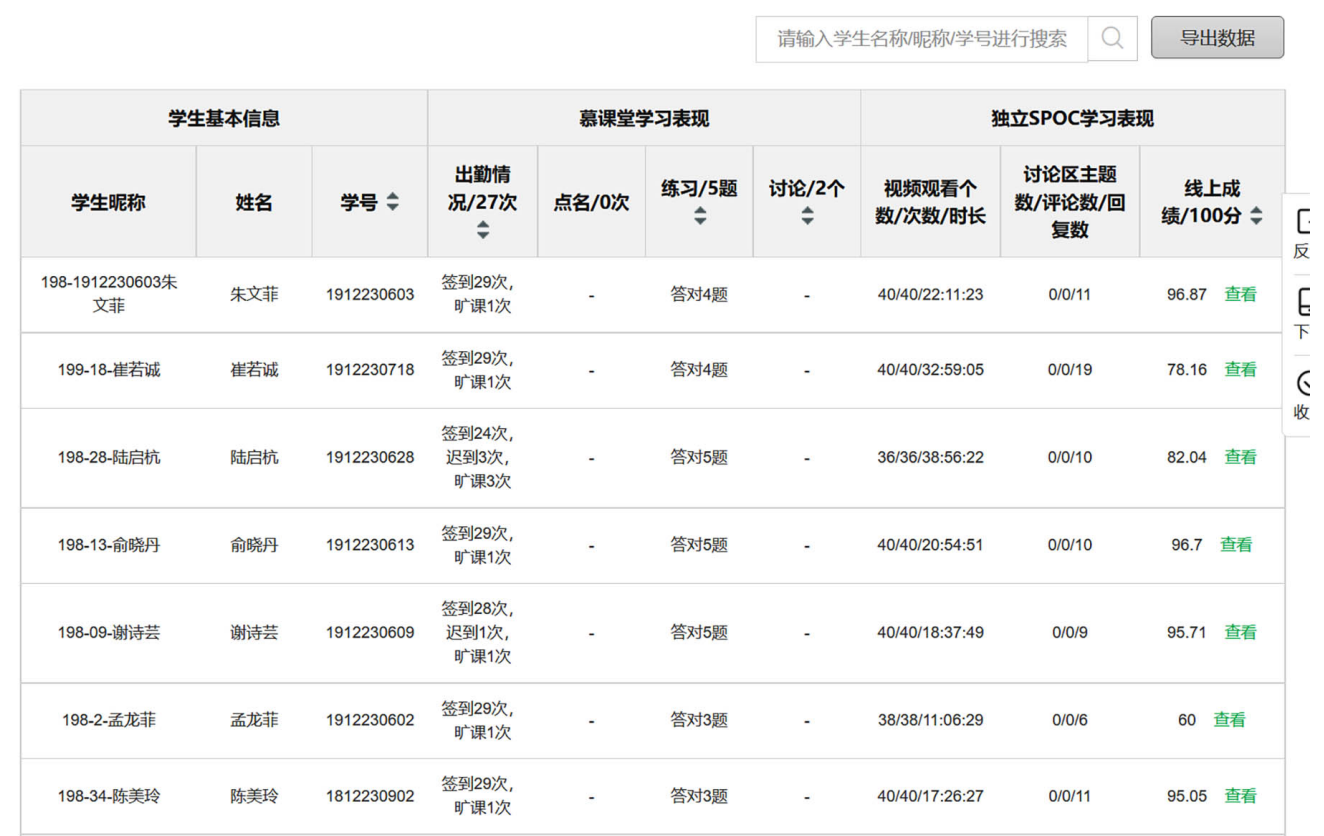

Figure 4. Classroom performance and independent SPOC learning performance. 


\subsection{Channels for Real-Time Interaction and Communication with Students}

Real-time interaction with students is not only reflected in the classroom. Problem discussion is a major feature of SPOC course. Teachers and students and students grow and progress together through research and discussion. For expansionary problems, thematic discussion posts are posted in the discussion area, and students speak through autonomous learning and thinking. In addition to the theme discussion area, SPOC platform also has in-class tests and in-class discussions. For the difficulties and problems encountered in practical learning, teachers and students also communicate through QQ, WeChat and other means to answer students' questions in time.

\section{Teaching Effect Evaluation}

The mixed teaching mode of circuit analysis course on SPOC platform is used in the two classes of 19 (8 and 9) majoring in electrical engineering and automation, with a total of 65 students participating. From February to the end of June 2020, the number of students learning on the SPOC platform in Love Course online school reached 167. There are 211 students majoring in electronics and Electric in grade 19 of our school. Besides the class, a large number of students have carried out SPOC self-study. Ten unit tests, 12 module assignments and one online examination were arranged, each with more than 100 submitters, or even up to 159. These figures show that using the SPOC platform for mixed teaching, the participation of students in the school is very high, which greatly improves the students' learning initiative and enthusiasm.

In order to improve the teaching, better serve the teaching, understand the students' opinions and suggestions on the teaching methods of the course, and constantly adjust and improve it in time, during the semester, we conducted two student satisfaction surveys on the SPOC platform mixed teaching mode of the circuit analysis course. One survey shows that $73.61 \%$ of the students are interested in mixed teaching on the SPOC platform, only $2.78 \%$ are not interested, $89.87 \%$ feel that the mixed teaching atmosphere is harmonious and active, and $94.44 \%$ of the students say that online learning is more enjoyable and interesting.

In order to further understand the students' understanding and feelings of this mixed teaching model, we randomly conducted in-depth interviews with 15 students in the class.

The interview results show that online teaching resources are helpful to understand the learning objectives and priorities, master knowledge and stimulate interest in learning. The new teaching model "has more room for autonomous learning and tests people's autonomous learning ability" and "through online communication and interaction with teachers and students, problems in learning can be solved at any time". But they also put forward some problems, such as "the learning task is heavy, there is not much time to log on to the learning platform", "the platform resources are not rich enough" and other problems are also problems that need to be solved in the follow-up teaching process. 


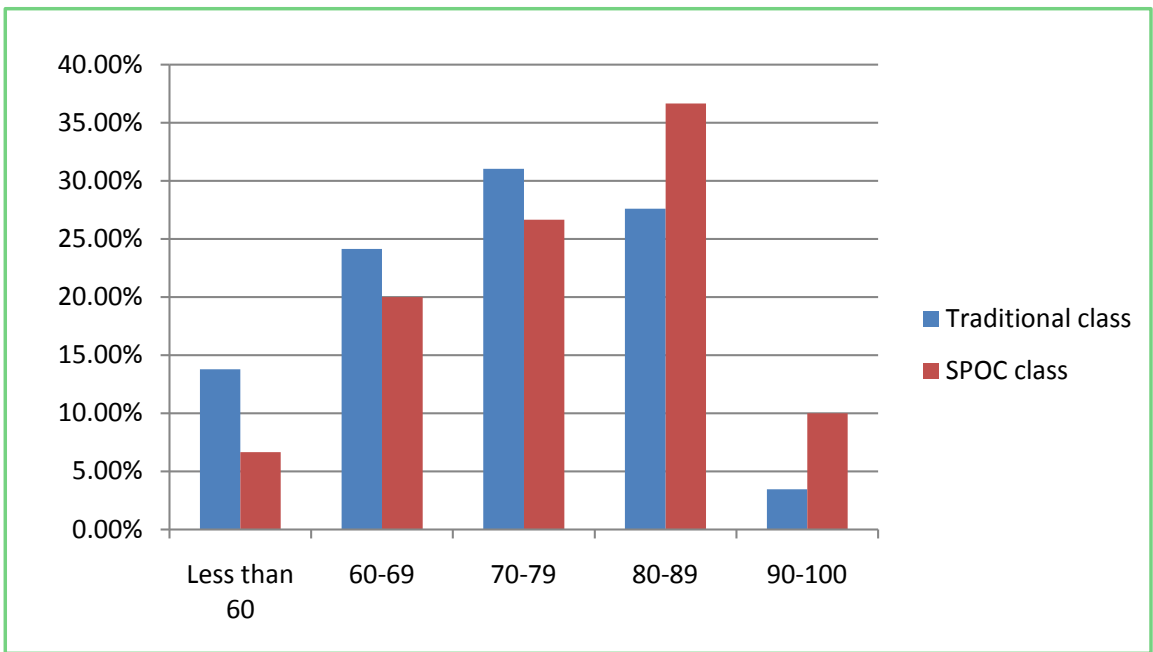

Figure 5. A comparison between SPOC class and traditional class in final examination.

Through questionnaire survey and in-depth interview, it is found that most students prefer this mixed teaching method. At the end of the course, a unified final exam was taken with the parallel class with the traditional teaching method. Figure 5 shows a comparison of the final exam scores between the SPOC class and the traditional class. Through the examination results can be seen, SPOC class in the examination papers of the excellent rate, pass rate, and other aspects, are better than the traditional teaching parallel classes.

\section{Conclusion}

\subsection{Achievement}

Since the implementation of mixed teaching of circuit analysis based on SPOC platform for one semester, some results have been achieved. Realize the transformation from teachers' teaching to students' learning, change from in class to in class and change from result evaluation to process result combination. Although students are the main body in the implementation, they put forward higher requirements for teachers. Before class, teachers need to carefully design the classroom content, refine knowledge points, refine various problems and tasks according to the students' learning situation. After class, students use fragmented time to learn at any time, study repeatedly, and ask questions to teachers in QQ at any time. Teachers need to spend more time and energy. Learning promotes teaching, teaching promotes learning, and students and teachers make common progress. Practice shows that hybrid teaching is a major reform of traditional teaching in concept, form and content, puts forward new challenges to teachers' teaching ability, students' learning habits and software and hardware environment, stimulates students' learning interest, cultivates students' autonomous learning ability, and improves teaching quality and learning efficiency.

\subsection{Deficiencies}

There are two main problems in the implementation of hybrid teaching practice 
based on SPOC: 1) A few students have no enthusiasm for learning and have video playback records, but they know nothing about the video content. SPOC platform learning is outside the classroom, so it is difficult for teachers to track the actual learning situation of students one by one; 2) Not all students have such high initiative or interest to deeply explore the knowledge points in SPOC platform. They are not good at asking questions, which directly affects the effect of flipped classroom. It takes some time for students to change from passive learning to active learning. In the process of exploration and implementation of hybrid teaching, they must constantly appear and solve problems.

\section{Conflicts of Interest}

The authors declare no conflicts of interest regarding the publication of this paper.

\section{References}

Fox, A. (2013). From MOOCs to SPOCs. Communications of ACM, 56, 38-40. https://doi.org/10.1145/2535918

Li, C. J., Fu, H. J., Yin, C. F., \& Chen, X. P. (2018). Practice of Classroom Teaching Model of Circuit Principle Reversal Based on SPOC. The World of Labor Security, 15, 75-76.

Sun, C. Z., \& Ding, Y. M. (2019). Reform and Practice of School-Based Personalized Hybrid Teaching of Circuit Principle Course under SPOC Mode. Journal of Dalian University, 6, 133-136.

Wang, R. (2018). Application of Flipped Classroom Based on SPOC on Circuit Analysis Course. Modern Educational Equipment in China, 295, 63-64.

Wang, Y. J., \& Yi, J. S. (2021). The Teaching Practice of the Hybrid Rollover Based on SPOC in Basic Circuit Analysis. Science and Technology, 4, 77-78.

Xie, N., Sun, W., \& Yu, S. J. (2017). Research on the Teaching Practice of Blended Instruction Based on SPOC. Computer Knowledge and Technology, 13, 122-123.

Yu, X. J. (2015). Student-Centred Teaching and Learning. Higher Education Press.

Zhang, Q., Zhang, H. F., Tang, Y., \& Yu, X. J. (2016). The Implementation of the Flipped Classroom Teaching Mode Based on SPOC Is Used in the Circuit Principle. Experimental Technology and Management, 33, 187-190.

Zhang, Y. (2020). On the Teaching Mode Reform of Basic Circuit Analysis Course. Electronic Production, 12, 62-63. 